HEFAT2014

$10^{\text {th }}$ International Conference on Heat Transfer, Fluid Mechanics and Thermodynamics

14 - 16 July 2014

Orlando, Florida

\title{
A STUDY ON THE AUTOIGNITION CHARACTERISTICS OF DME-LPG DUAL FUEL IN HCCI ENGINE
}

\author{
Jamsran N. and Lim O.T.* \\ *Author for correspondence \\ School of Mechanical Engineering, \\ University of Ulsan, \\ Ulsan, 680-749, \\ South Korea, \\ E-mail: otlim@ulsan.ac.kr
}

\begin{abstract}
This study was investigated to examine the potential increase of engine power through the mixture of di-methyl ether (DME) and liquefied petroleum gas (LPG) on homogeneous charge compression ignition (HCCI) combustion. The effects of mixing ratio of DME/LPG in constant intake temperature were confirmed experimentally in a single cylinder diesel engine. A numerical analysis were conducted through the mixing model of DME and n-Butane for the detailed chemical kinetics using CHEMKIN-PRO to clarify the autoignition mechanism of constant combustion phasing. The results show that the increased amount of LPG reduces the low temperature heat release (LTHR) and activates the high temperature heat release (HTHR) which increases the in-cylinder pressure. Therefore, it has potential to raise the indicated mean effective pressure (IMEP) by appropriately changing the mixing ratio. Also, thermal efficiency was increased to $51.2 \%$ at the mixing ratio of 0.6. Finally, engine out emissions including total hydrocarbon (THC) and carbon monoxide (CO) were decreased by the change of mixing ratio. Numerical results agreed with experiment that the weakened low temperature oxidation by the increase of n-Butane amount.
\end{abstract}

\section{INTRODUCTION}

The HCCI engine is named as the candidate of next generation internal combustion engine with the high efficiency of the compression ignition (CI) engine and the very low emissions of the spark ignition (SI) engine. The known benefits of a HCCI engine are near-zero nitrogen oxides (NOx) and PM emissions. However, several items have to solve before its widespread production. Controlling the rate of energy release and pressure-rise at high loads have been main problems [1].

There are many attempts made to overcome the problem of early ignition timing, which are making heterogeneous mixture or thermal stratification [2-5], adding cooled exhaust gas recirculation (EGR) [6], and mixing two different characteristics of fuels as high cetane and high octane number fuels [7], or vice versa. Among them, fuel selections for large reactivity difference fuels have been one of the important aspects of HCCI engine development. Adjusting the appropriate proportions of high cetane number fuel and high octane number fuel may control the ignition timing and expand the operation range of HCCI combustion. To approach that way, DME and LPG were used in this study as a fuel. DME has been taking much attraction as known the alternative of diesel fuel with smokeless combustion, low ignition temperature, superior properties of evaporation and available to produce from wide ranges of sources as natural gas, coal and vegetarian, etc. Besides these good characteristics, early ignition and short burn duration have been main obstacle and limits the wide production of DME fueled vehicles or the other applications [811]. On the other hand, LPG has similar characteristics with DME while it has $40 \%$ higher value of lower heating than that of DME. Therefore, adding LPG into DME as ignition inhibitor is the promising technology [12-14]. Since normal butane is main component of LPG, authors have conducted a modeling work on DME/n-Butane pre-mixture which shows that optimized mixing ratio has the potential to delay autoignition timing by reducing pressure rise rate (PRR). This is a continued work to get better understanding in the aspect of fundamentals for reaction mechanism since ignition of HCCI takes place by the dominance of chemical kinetics.

The main objective of this study is to computationally investigate the autoignition mechanism of the DME/n-Butane mixture in case of chemical kinetics. The "Contribution matrix to heat release" and "Absolute heat-release rate" of important elementary reactions are used for each fuel to identify the underlying mechanism by varying the mixing ratios.

\section{EXPERIMENTAL SETUP}

Figure 1 shows a schematic of engine which is a single cylinder diesel engine with a displacement of $498 \mathrm{cc}$. The 
engine specifications are showed in Table 1. From the left side of the schematic, intake system, engine and exhaust system are shown. Air was supplied from the intake system with naturally aspirated and metered by the air flow meter. Fuel was injected

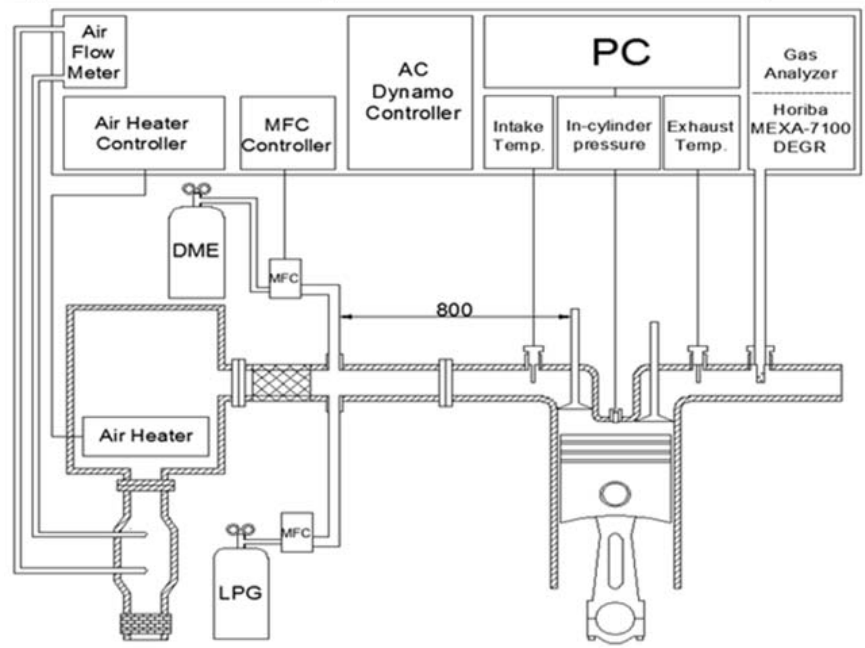

Figure 1 Schematic of the engine facility.

Table 1 Engine specifications

\begin{tabular}{lll}
\hline & Experiment & Calculation \\
\hline Process & 4 stroke & $\begin{array}{l}\text { Only one } \\
\text { comp./expansion }\end{array}$ \\
& & - \\
Number of cylinders & 1 & $\leftarrow$ \\
Displaced volume & $498 \mathrm{cc}$ & $\leftarrow$ \\
Stroke & $92 \mathrm{~mm}$ & $\leftarrow$ \\
Bore & $83 \mathrm{~mm}$ & $\leftarrow$ \\
Connecting Rod & $145.8 \mathrm{~mm}$ & $\leftarrow$ \\
Compression ratio & $19.5: 1$ & $\leftarrow$ \\
Number of Valves & 2 & $\leftarrow$ \\
Inlet Valve Close & $136^{\circ} \mathrm{bTDC}$ & $\leftarrow$ \\
Exhaust Valve Open & $125.4^{\circ}$ aTDC & $\leftarrow$ \\
Fueling system & Fully premixed & $\leftarrow$ \\
\hline
\end{tabular}

from the distance of $800 \mathrm{~mm}$ of the intake valve. The reason for the distance from the intake valve was to maximize the premixture of fuel and air. The temperatures for pre-mixture and exhaust gas were measured by the temperature sensors which were installed at intake valve and exhaust valve, respectively. The in-cylinder pressure was measured by the pressure sensor which was located at the center of the cylinder head.

DME and LPG were used as a fuel by injecting into the intake manifold to make the pre-mixture. DME was the main fuel. Dual fuel's mixing ratio was defined by the following equation and mixing ratios as well equivalence ratios regarding to the mixing ratio of each fuel are shown in equation 2 .

$$
X_{D M E}=D M E(g / \text { cycle }) /(D M E(\text { g / cycle })+L P G(\text { g / cycle }))
$$

\section{NUMERICAL METHOD}

The computational investigations were conducted using the single-zone model of CHEMKIN included in CHEMKIN-PRO [15]. The single-zone model treats the in-cylinder charge as a single lumped mass with uniform composition and thermodynamic properties. Heat-transfer and blow-by effects were not included. Compression / expansion was modeled according to the standard slider-crank relationship [16], using the geometry and specifications of the single-cylinder HCCI engine as shown in Table 2. The calculation starts from the intake valve close (IVC) of $136^{\circ}$ bTDC to the exhaust valve open (EVO) of $125.4^{\circ}$ aTDC. The single-zone model allows relatively short computational times even with the detailed chemical-kinetic mechanisms, so numerous changes in operation conditions can be readily examined. In this modeling work, the ratio of DME and n-Butane was defined by the following equation.

$$
X_{D M E}=\frac{n_{D M E}(\mathrm{~mol} / \mathrm{cycle})}{n_{D M E}(\mathrm{~mol} / \mathrm{cycle})+n_{n-B u t a n e}(\mathrm{~mol} / \mathrm{cycle})}
$$

$n_{D M E}:$ mole number of DME during 1 cycle

$n_{n-\text { Butane }}$ : mole number of n-Butane during 1 cycle

Chemical kinetic scheme for the mixture of two fuels with 185 species and 730 reactions was created through the models from Curran's di-methyl ether (DME) [17-18] and Kojima's nButane [19] whose chemical kinetics mechanisms and thermodynamic parameters were used. Therefore, the validation of this new mixing model was conducted using shocktube calculation and the results shown in Figure 1 for the ignition delay as a function of intake-temperature in case of mixture ratio.

Solid lines are results of the mixing model while circle and rectangular points are the data from original models of DME and n-Butane. As can be seen in the figure, ignition delay of the mixture increases as the amount of n-Butane under $1100 \mathrm{~K}$ is increased due to the long ignition delay characteristics of nButane at lower temperature. However, the ignition delay timing was nearly similar at higher intake temperatures between $1100 \mathrm{~K}$ and $1600 \mathrm{~K}$. In general, because of the near similarity of experimental data of DME and n-Butane for the temperature range, mixing model was thought to be utilized for further calculation through its validation with experimental data [17-19]. Properties of these fuels are showed in Table 3.

DME fuel is considered a promising clean alternative fuel for ground transportation vehicles, and it can be substitute for conventional diesel fuel in a compression ignition diesel engine [11]. n-Butane has low cetane number characteristics and is not able to ignite itself as DME. Molecular ratio of air was as follows N2:O2:Ar = 78:21:1. For this modeling study, no attempt is made to capture the effect of trace hydrocarbon species such as carbon monoxide (CO), hydrocarbons (HC) and partially-oxidized hydrocarbons encountered experimentally in real EGR. The beginning of the main heat release marks the onset of hot chemistry with breaks down of $\mathrm{H} 2 \mathrm{O} 2$ at temperature around $1100 \mathrm{~K}$. Refer to the maximum temperature, the onset of misfire reactions can be judged when reaching the 
temperature below $1100 \mathrm{~K}$ [20]. Reactions involved dominantly in the autoignition of DME and n-Butane were divided in three main groups which are fuel series reactions, $\mathrm{H} 2 \mathrm{O} 2$ loop reactions and hydrogen-oxygen (H2O2) system reactions, which are illustrated in Figure 3.

Table 2 Mixing ratio definition and equivalence ratio.

\begin{tabular}{c||l|l|l|l}
\hline $\begin{array}{l}\text { Mixing ratio of } \\
\text { DME, } X_{\text {DME }}[-]\end{array}$ & $\begin{array}{l}\text { DME } \\
{[\%]}\end{array}$ & $\begin{array}{l}\text { LPG } \\
{[\%]}\end{array}$ & $\begin{array}{l}\varphi_{\text {DME }} \\
{[-]}\end{array}$ & $\begin{array}{l}\varphi_{\text {n-Butane }} \\
{[-]}\end{array}$ \\
\hline \hline 1.0 & 100 & 0 & 0.57 & 0.00 \\
\hline 0.9 & 90 & 10 & 0.51 & 0.06 \\
\hline 0.8 & 80 & 20 & 0.45 & 0.12 \\
\hline 0.7 & 70 & 30 & 0.39 & 0.18 \\
\hline 0.6 & 60 & 40 & 0.34 & 0.23 \\
\hline 0.5 & 50 & 50 & 0.28 & 0.29 \\
\hline 0.4 & 40 & 60 & 0.22 & 0.35 \\
\hline 0.3 & 30 & 70 & 0.17 & 0.40 \\
\hline 0.2 & 20 & 80 & 0.11 & 0.46 \\
\hline 0.1 & 10 & 90 & 0.05 & 0.52 \\
\hline 0.0 & 0 & 100 & 0.00 & 0.57 \\
\hline
\end{tabular}

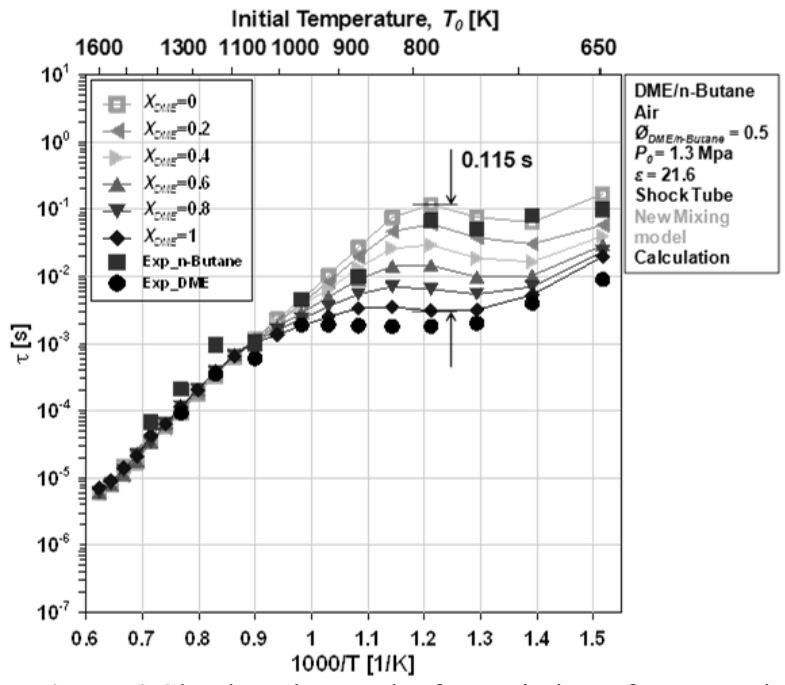

Figure 2 Shock-Tube results for variation of DME ratios vs. experimental ignition delays (points) for DME [17-18] and nButane [19].

Table 3. Fuel properties

\begin{tabular}{|c|c|c|c|c|}
\hline Items & DME & n-Butane & Diesel & Gasoline \\
\hline Molecular Formula & $\mathrm{CH}_{3} \mathrm{OCH}_{3}$ & C4H10 & - & - \\
\hline $\begin{array}{l}\text { Low Heat Value } \\
{[\mathrm{MJ} / \mathrm{kg}]}\end{array}$ & 28.8 & 45.8 & 42.7 & 43.2 \\
\hline Cetane Number & $55-60$ & $<10$ & $40-55$ & $13-17$ \\
\hline $\begin{array}{l}\text { LTHR / Total HR } \\
* 100[\%]\end{array}$ & $10 \sim 30$ & $0 \sim 5$ & - & - \\
\hline $\begin{array}{l}\text { HTHR / Total HR } \\
* 100[\%]\end{array}$ & 70 90 & $95 \sim 100$ & - & - \\
\hline
\end{tabular}

The autoignition process can be simplified by the extracting important reactions from detailed chemical kinetics mechanisms using "contribution matrix to heat release" [21] as shown in Eq.3.

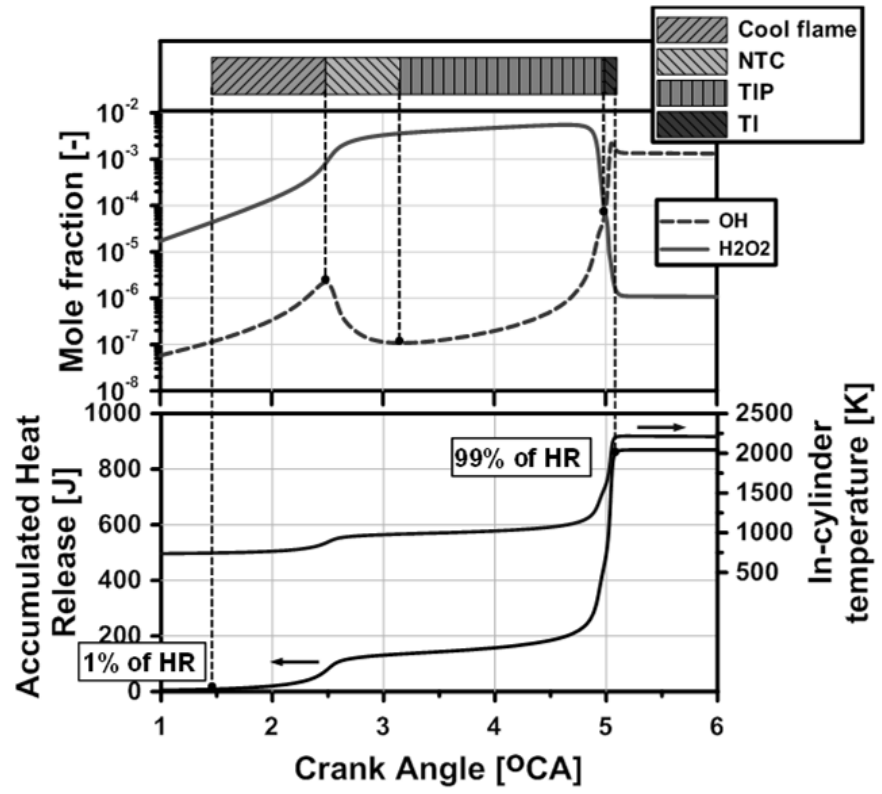

Figure 3. Definition of key combustion timings.

$$
C H R_{j, T t}=\frac{H R_{j, T t}}{\sum_{j=1}^{N} a b s\left(H R_{j}, T_{t}\right)} \cdot 100 \%
$$

Here, CHRj,Tt is the contribution ratio of $\mathrm{jth}$ elementary reaction to heat release at a transient temperature $\mathrm{Tt}$. $\mathrm{HRj}, \mathrm{Tt}$ is the heat release rate by the jth elementary reaction at $\mathrm{Tt}$. This study utilized the data for the value of contribution ratio to heat release of important elementary reactions above 3\% at $\mathrm{Tt}$.

\section{TRENDS AND RESULTS}

\section{Effects of Mixing Ratios on Combustion Phasing}

오류! 참조 원본을 찾을 수 없습니다. shows the combustion characteristics for the change of mixing ratio of DME and LPG at same input calorific value in experiment. Incylinder pressure was increased till mixing ratio of 0.7 but decreased when mixing ratio was less than 0.6. The peak pressure was abruptly reduced as $4.19 \mathrm{MPa}$ from $\mathrm{X}_{\mathrm{DME}}=0.5$ and the amount of heat release was also decreased. From less than 0.4 of mixing ratio, the in-cylinder temperature was lower than $1100 \mathrm{~K}$. It can be seen that combustion phasing has been retarded by the LPG content and duration was reduced due to higher energy density of LPG in the mixture. Figure 5 shows the IMEP and thermal efficiency for the various mixing ratio. COV of IMEP took its peak at $\mathrm{X}_{\mathrm{DME}}=0.5$ as $42 \%$ while its normal value should be within $8 \%$ [22-23].

As mentioned before, the ratios are lower than 0.5 results in the misfire operation. Therefore, IMEP was the highest at 0.6 for considering above conditions, where IMEP and thermal efficiency were increased by $250 \mathrm{kPa}$ and $28.2 \%$, respectively, 
compared to $\mathrm{XDME}=1.0$. The combustion process takes place around the beginning of expansion stroke for the highest IMEP condition as $\mathrm{XDME}=0.6$. Therefore, the low temperature heat release (LTHR) was decreased while the high temperature heat release (HTHR) was increased for the change of mixing ratio. From the data-set for emissions in Figure 6, the amount of THC and $\mathrm{CO}$ was decreased at the combustion zone where the incylinder temperature was higher than $1500 \mathrm{~K}$.

NOx emissions were resulted very low since the in-cylinder temperature was lower than $2200 \mathrm{~K}$ for all the cases of combustion zone. Typically, $\mathrm{HC}$ and $\mathrm{CO}$ were generated when the in-cylinder temperature was lower than $1500 \mathrm{~K}$ due to the no decomposition process from $\mathrm{H} 2 \mathrm{O} 2$ to $\mathrm{OH}$ at lean and cold side of the cylinder [24-25].
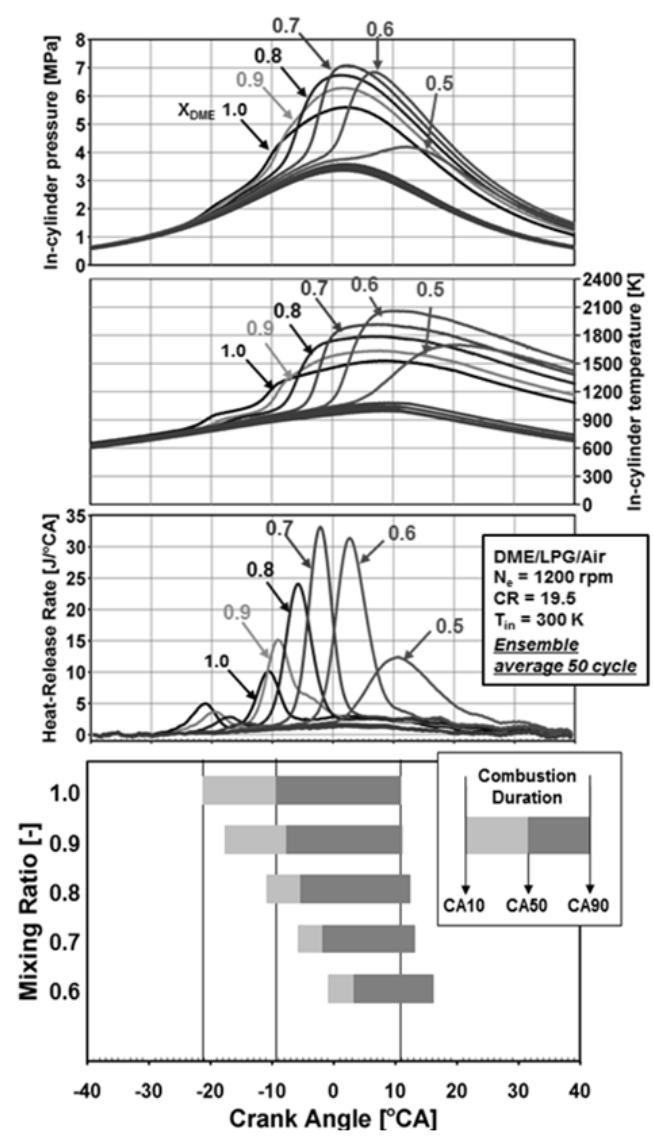

Figure 2 In-cylinder pressure, temperature, heat release and combustion duration as a function of mixing ratio.

\section{Modeling of Results for the Mixing Ratio}

Figure 7 shows the comparison of modeling results for simulation with experiment. To match the results from the modeling to experiment, the compression ratio was adjusted by reducing to 15 since there was no heat transfer effect in the modeling. In order to obtain the fundamental knowledge about the autoignition process of the two fuels of mixture, chemical kinetic modeling study was exercised.

The supplied fuel/ air equivalence ratio was 0.57 and intake caloric value was $770 \mathrm{~J} /$ cycle throughout the change of mixing

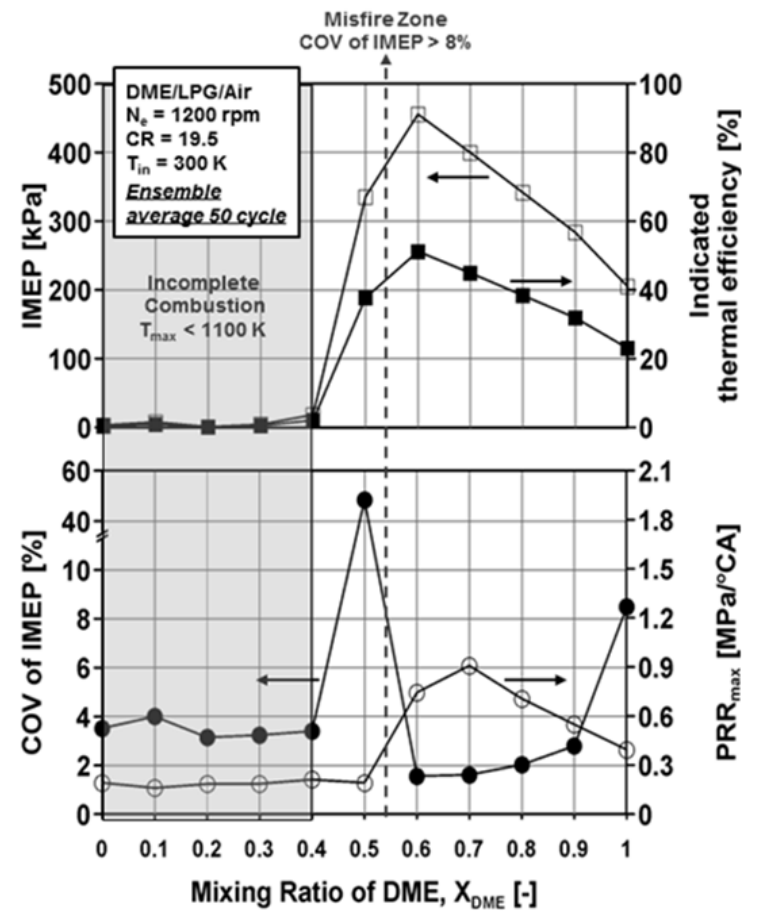

Figure 3 IMEP, indicated thermal efficiency, COV of IMEP and maximum pressure rise rate for the mixing ratio of DME.
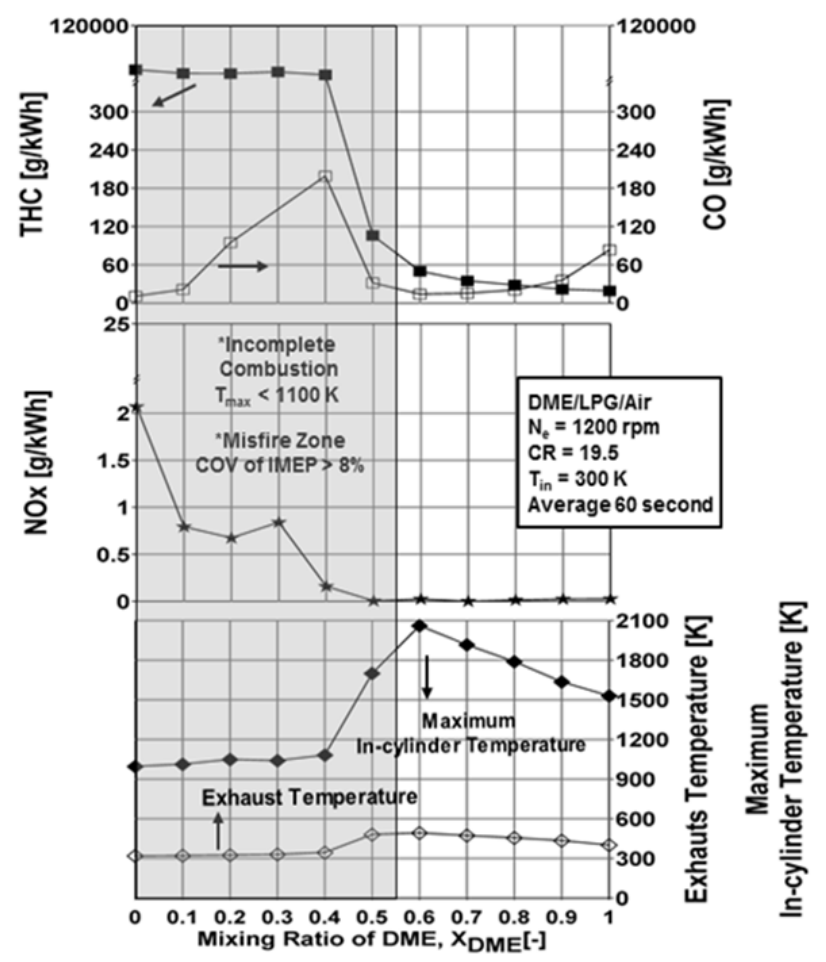

Figure $6 \mathrm{THC}, \mathrm{CO}$, NOx emissions, exhaust gas temperature and maximum in-cylinder temperature as a function of mixing ratio of DME for same operating condition shown in Fig. 5.

ratio to maintain the effect of fuel. Also, the mole number was fixed by the value of the base point which was selected for $\mathrm{XDME}=1.0,300 \mathrm{~K}$ and $0.1 \mathrm{MPa}$. Therefore, the mole number 


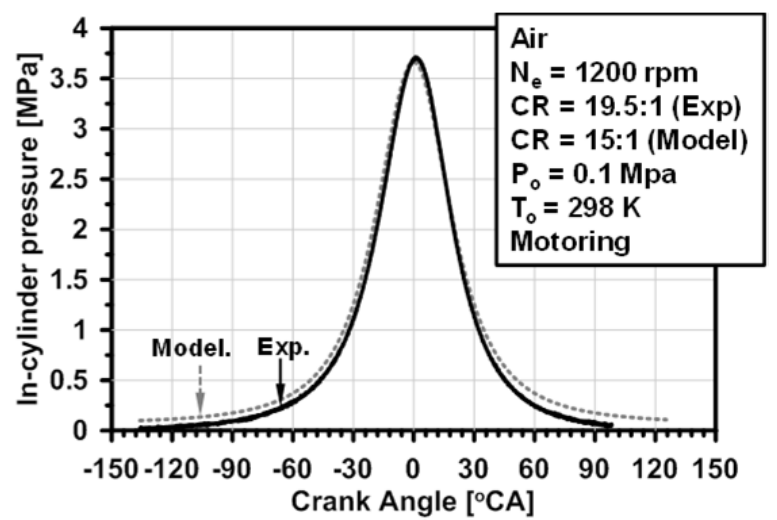

Figure 7 Comparison of in-cylinder pressure traces of motoring for the model and experiment.

and intake calorific value were fixed constant by adjusting the intake pressure and temperature with the change of mixing ratio. Figure 8 shows how the intake pressure and temperature must be changed to obtain above mentioned baseline point and combustion duration and key combustion temperatures were shown.

As the reduce of n-Butane amount in the mixture, both intake temperature and pressure dramatically reduced. The lower cetane number of $\mathrm{n}$-Butane shows the slow autoignition reactivity. The combustion duration was increased by the lengthen of TIP as the increase of n-Butane amount in the mixture. There was single stage combustion occurred as the mixture ratio increased over 0.3 , where the combustion duration was the longest. The combustion temperatures were reduced at DME side since its intake pressure and temperatures were lower than that of n-Butane side. Cool flame start temperature was increased but other temperatures were decreased at n-Butane side. Figure 9 shows PRR, RI and IMEP as a function of mixing ratio for the data plotted in Fig.8. PRR and RI were gradually increased as the increase of n-Butane from 0.4 .

IMEP resulted the identical amount and no such big difference between the mixing ratios. Therefore, in Fig.9, mixing ratio 0.5 and 1.0 were compared to confirm the influences on autoignition and how it differs during the combustion process in view point of chemical kinetics. Although the effects of the mixing ratio were briefly explained above, its mechanism on autoignition is still unclear. What factor is influenced on the increase of combustion duration by reduced combustion temperature? In order to clarify the underlying mechanism and answer the question, the heat release of elementary reactions involved in the autoignition were separately considered with autoignition regimes. Therefore, contribution matrix to heat release in which reactions were above the threshold as $3 \%$ was utilized and it gives the possibility to distinguish the important reactions participated in autoignition process of DME/n-Butane HCCI combustion. As can be seen in the Fig.10, absolute heat release for overall dominant reactions and rates of those reactions in separate autoignition regimes for $\mathrm{X}_{\mathrm{DME}}=0.5$ and 1.0 were selected for the comparison.

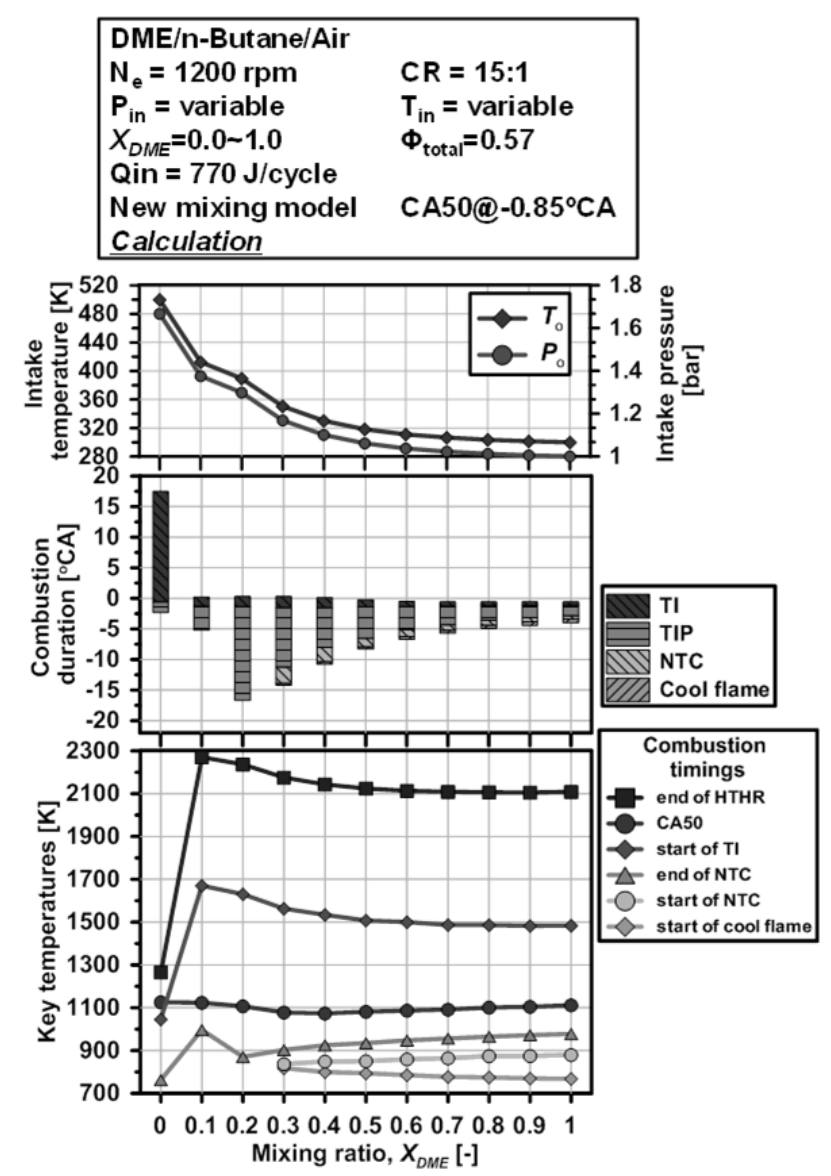

Figure 8 Effect of mixing ratio on required intake temperature, combustion duration and key combustion temperatures in constant phasing operation.

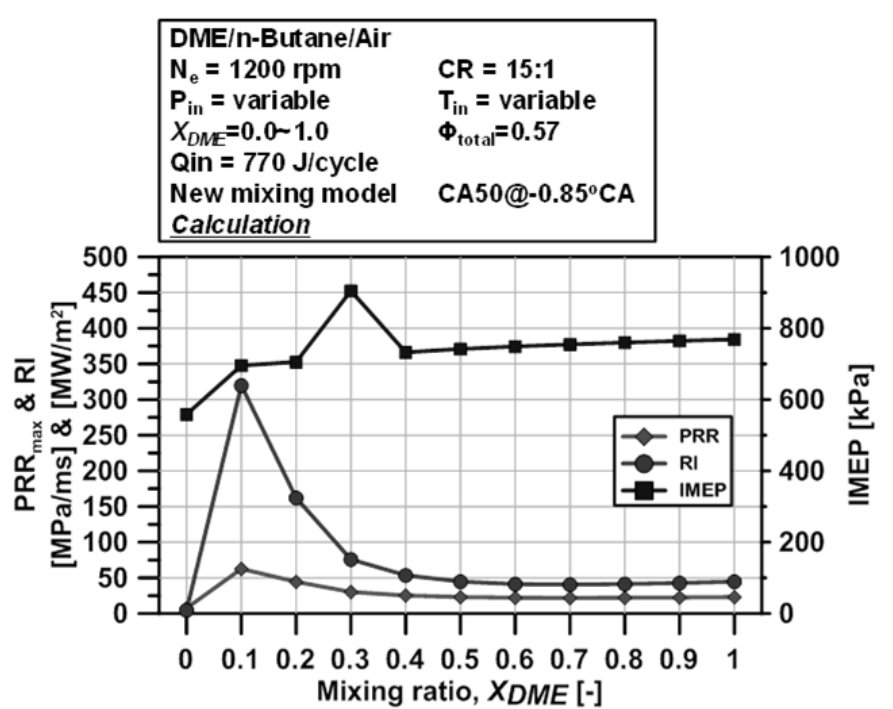

Figure 9 Effect of mixing ratio of DME on PRR, ringing intensity (RI) [3] and IMEP for the data plotted in Fig. 8.

As can be seen from the legend at the top left side of the figure, absolute HRR is black line, which was higher abs.HRR and longer temperature duration at $\mathrm{XDME}=1.0$ compared to 0.5 . To 

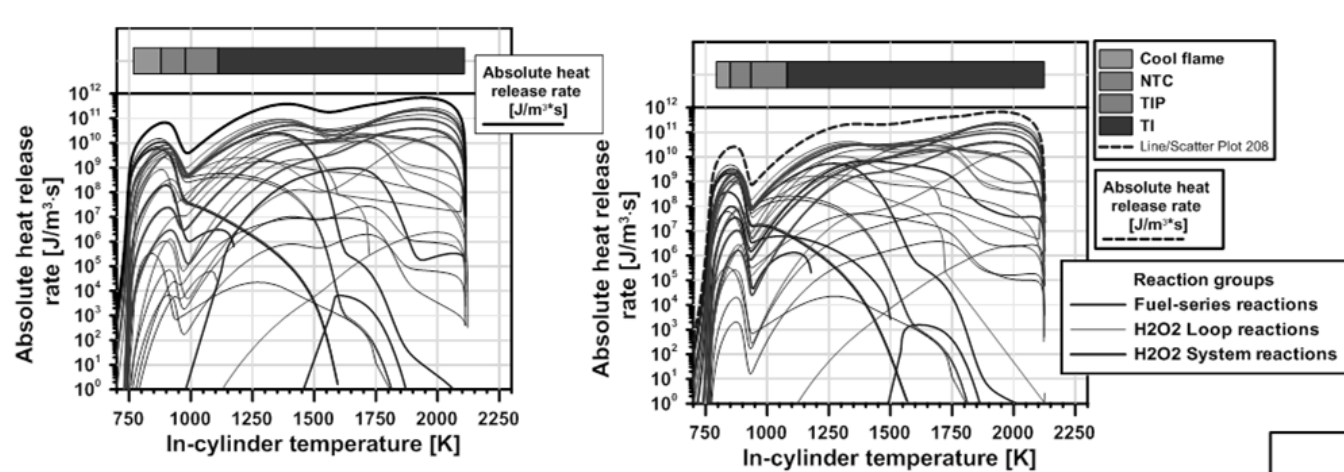

DME/LPG/Air

$\mathrm{N}_{\mathrm{e}}=1200 \mathrm{rpm}$

$C R=15: 1$

$P_{\text {in }}=0.1061 \mathrm{Mpa}\left(X_{D M E}=0.5\right)$

$P_{\text {in }}=0.1 \mathrm{MPa}\left(X_{D M E}=0.1\right)$

$\mathrm{T}_{\text {in }}=318.3 \mathrm{~K}\left(X_{D M E}=0.5\right)$

$\mathrm{T}_{\text {in }}=300 \mathrm{~K}\left(X_{D M E}=0.1\right)$

$\Phi_{\text {total }}=0.57$

Qin $=770 \mathrm{~J} /$ cycle

New mixing model

CA50@- $0.85^{\circ} \mathrm{CA}$

Calculation
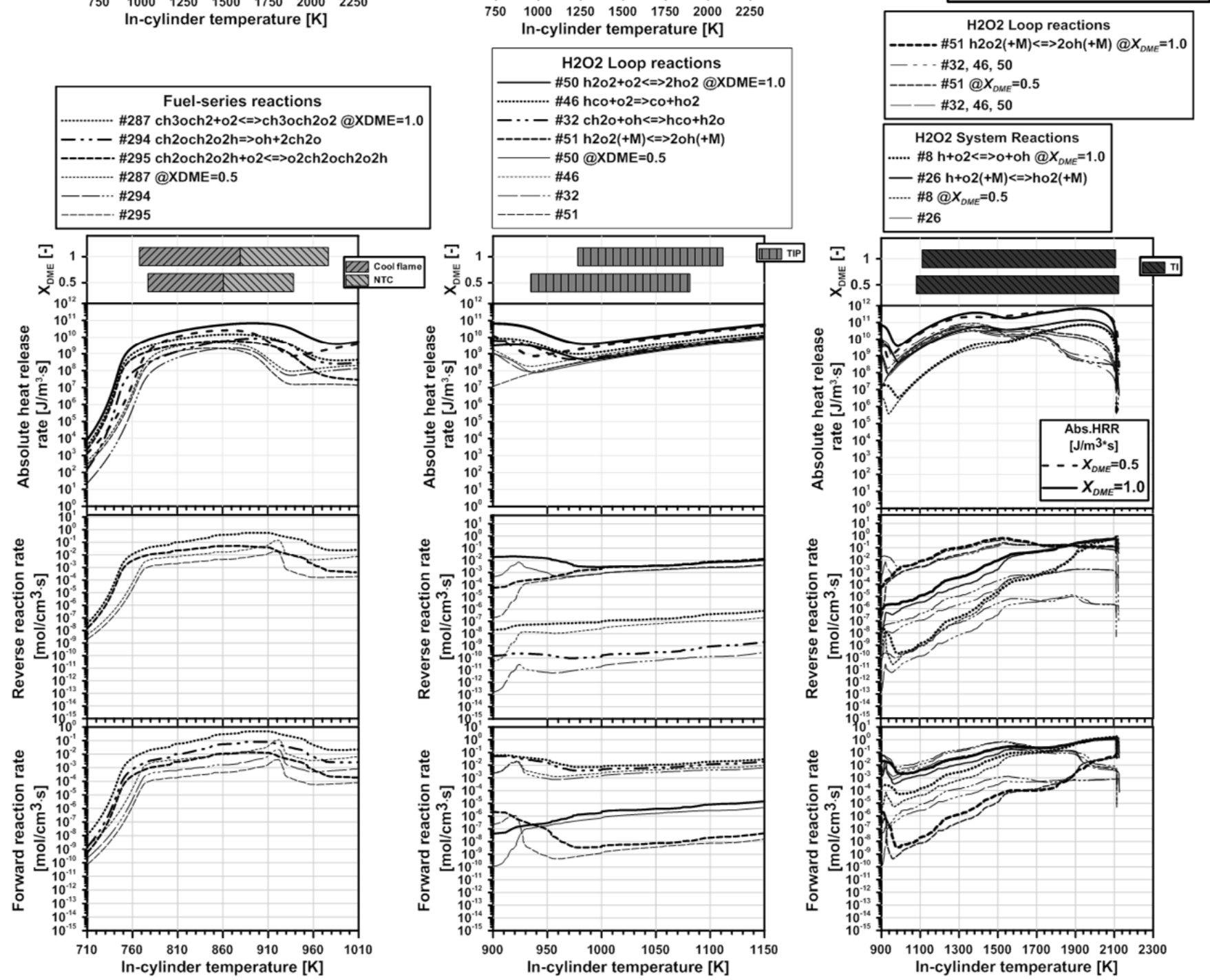

Figure 10 Absolute HRR and reaction rates for dominant reactions in autoignition of DME/n-Butane HCCI combustion in case of $\mathrm{XDME}=0.5$ and 1.0 .

better understand these phenomena, the elementary reactions were divided into three main groups as fuel-series, $\mathrm{H} 2 \mathrm{O} 2$ loop, and $\mathrm{H} 2 \mathrm{O} 2$ system reactions [22].

Reaction 294 is transition reaction from cool-flame to NTC which suppresses the reaction rate. The equilibrium of these reactions shift toward the reactants side and the addition of $\mathrm{O} 2$ to the alkyl radical is almost completely extinguished with the higher temperatures. The temperature range for cool flame
Cool-flame and NTC range: Among the fuel- series reactions, primary $\mathrm{O} 2$ addition by 287 reaction and secondary $\mathrm{O} 2$ addition by 295 reaction are dominant in cool flame. surrounded between $770 \mathrm{~K}$ and $880 \mathrm{~K}$ for $\mathrm{XDME}=1.0$ while it was started at $780 \mathrm{~K}$ and transmitted at $860 \mathrm{~K}$ to NTC range for 0.5 . It was thought that the existence of n-Butane shortens the temperature range of cool flame. In case of NTC, it was terminated at $980 \mathrm{~K}$ and $924 \mathrm{~K}$ for the cases, respectively. The lower transition 
temperature of cool flame to NTC was a reason for longer duration of NTC in Fig.8. In order to comprehend the underlying mechanism of this event, reaction rates of both reverse and forward were plotted along with the in-cylinder temperature for autoignition ranges. Reactions go follow a similar trend to absolute HRR within these regions. Absolute HRR of primary $\mathrm{O} 2$ addition reaction (287) was higher at $\mathrm{XDME}=1.0$ than that of 0.5 case. Around $860 \mathrm{~K}$ for 0.5 , decomposition reaction (294) was crossed with secondary O2 addition reaction (295) and went upward since its forward reaction rate was increased, which was taken place around $870 \mathrm{~K}$ for $\mathrm{XDME}=1.0$. Therefore, HRR for the reaction (294) was responsible for the occurrence of NTC, which was solely increased at the transition region of NTC from cool flame. In both cases, reverse reaction of 294 was not taken place. During the NTC range, rates of all reactions were decreased and terminated at $980 \mathrm{~K}$ and $920 \mathrm{~K}$ for both cases. Mainly this trend was comparable with combustion duration. In both cases, the minimum transient temperature of reaction 294 for HRR after the first peak was matched up to the end of NTC.

Thermal-ignition preparation and thermal ignition: The role of TIP reactions is to increase the temperature to initiate the TI. After the fuel series reactions, $\mathrm{H} 2 \mathrm{O} 2$ loop reactions were the main contributor to TI range in TIP range, which plays an important role in the thermal ignition by supplying heat rather than radicals. During the NTC range, almost reactions rates and heat release decreased but the only reaction was increased without falling down along with the increase of the in-cylinder temperature which was $\mathrm{H} 2 \mathrm{O} 2$ decomposition reaction (51) to generate $\mathrm{OH}$. TIP begins around $980 \mathrm{~K}$ and $925 \mathrm{~K}$ after NTC in both cases. At $\mathrm{XDME}=0.5$, NTC was terminated at lower temperature and TIP was started and went through the lower reaction rates, in which forward reaction rates were decreased as the in-cylinder temperature is increased. This is the reason of slowed down of autoignition with lower heat release and longer burn duration at TIP range. It can be also confirmed in combustion duration in Fig.7, where TIP was lengthened evidently at $\mathrm{XDME}=0.5$. In $\mathrm{TI}$ range, although there are a number of reactions contributed as plotted in the absolute heat release graph on top of figure, hydrogen-oxygen system reaction was initiated by the decomposition of $\mathrm{H} 2 \mathrm{O} 2$ and the increase of $\mathrm{OH}$, in which the competition of branching chain reaction (8) and $\mathrm{HO} 2$ recombination reaction (26) are dominant along with temperature. As the temperature increase after TIP, reaction (51) of $\mathrm{H} 2 \mathrm{O} 2$ loop was also contributor to take place of thermal ignition among the other reactions, of which reaction rates are higher than other reactions of loop. Reverse reaction rates of $\mathrm{XDME}=0.5$ were higher than that of $\mathrm{XDME}=1.0$ case, while it was inverse at forward reaction rate. This higher reverse reaction rate of $\mathrm{H} 2 \mathrm{O} 2$ loop reactions at $\mathrm{XDME}=0.5$ case might be responsible for evidently longer TIP duration. At $\mathrm{XDME}=0.5$, combustion temperature was lower and duration of TI was longer even CA50 was identical with $\mathrm{XDME}=1.0$. At forward reaction rate of $\mathrm{XDME}=0.5$, the competition of reaction (8) and (26) was not strong and it terminates at lower temperature. It was thought that the reason of increased duration of TI along with crank angle.

\section{CONCLUSION}

In this work, we attempted to increase the engine output by mixing of DME and n-Butane. Based on the experimental results, numerical work was conducted to understand the autoignition process in view point of chemical kinetics. From this study, the following conclusions can be drawn:

1. IMEP was increased slightly when XDME was changed from 1.0 to 0.6 and took the peak value $(455 \mathrm{kPa})$ at mixing ratio of 0.6 due to the higher energy content of n-Butane compared to pure DME.

2. Thermal efficiency was similar trend with IMEP and had the maximum value at 0.6 as $51.2 \%$.

3. The minimum values for $\mathrm{THC}$ and $\mathrm{CO}$ belonged to the mixing ratio of DME at 1.0 and 0.6 respectively. THC and $\mathrm{CO}$ were simultaneously reduced when XDME was 0.8. NOx almost does not exist.

4. New mixing model of DME and n-Butane mixture was validated successfully and followed the data under the condition of experimental study. Low temperature oxidation reactions were weakened with increased n-Butane content and decreased the temperature of high temperature oxidation. However, reaction paths of the HTO were identical during the temperature from 1000 to $2100 \mathrm{~K}$.

\section{REFERENCES}

[1] Zhao F., Asmus T.W., and Assanis D.N., Dec J.E., Eng J.A., Najt P.M. (Eds.), Homogeneous charge compression ignition (HCCI) engines: Key Research and Development Issues, Society of Automotive Engineers, Warrendale, PA, 2003.

[2] Yang Y., Dec J.E., Dronniou N., and Sjöberg M., Tailoring HCCI heat-release rates with partial fuel stratification: Comparison of two-stage and single-stage-ignition fuels, Proceedings of the Combustion Institute. Vol. 33, 2011, pp. 3047-3055.

[3] Yang D., Wang Z., Wang J., and Shuai S., Experimental study of fuel stratification for HCCI high load extension, Applied Energy, Vol. 88 (9), 2011, pp. 2949-2954.

[4] Zhang H., Hawkes E.R., Chen J.H., and Kook S., A numerical study of the autoignition of dimethyl ether with temperature inhomogeneities, Proceedings of the Combustion Institute. Vol. 34 2013, pp. 803-812.

[5] Peterson B., Baum E., Böhm B., Sick V., and Dreizler A., High-speed PIV and LIF imaging of temperature stratification in an internal combustion engine, Proceedings of the Combustion Institute. Vol. 34, 2013. Pp. 3653-3660.

[6] Sjöberg M., and Dec J.E., Effects of EGR and its constituents on HCCI autoignition of ethanol, Proceedings of the Combustion Institute. Vol. 33, 2011, pp. 3031-3038.

[7] Shi S., Recent progress in combustion technologies for automotive engines, J Combust Sci Technol, Vol. 7, 2001, pp. 1-15.

[8] DME Handbook, Japan DME forum, Ohmsha Ltd, Japan, 2007.

[9] Semelsberger T.A., Borup R.L., and Greene H.L., Dimethyl ether (DME) as an alternative fuel, Journal of Power Sources. Vol. 156, 2006, pp. 497-511.

[10] Arcoumanis C., Bae C., Crookes R., and Kinoshita E., The potential of di-methyl ether (DME) as an alternative fuel for compression-ignition engines: A review, Fuel, Vol. 87, 2008, pp. 1014-1030. 
[11] Park S., and Lee C., Combustion performance and emission reduction characteristics of automotive DME engine system. Progress in Energy and Combustion Science, Vol. 39, 2013, pp. 147-168.

[12] Oh C., Jang J., Bae C., The effect of LPG composition on combustion and performance in a DME-LPG dual-fuel HCCI engine, SAE paper 2010-01-0336, 2010.

[13] Lu X., Han D., and Huang Z., Fuel design and management for the control of advanced compression-ignition combustion modes, Progress in Energy and Combustion Science, Vol. 37, 2011, pp.741783.

[14] Lee S., Oh S., Choi Y., and Kang K., Effect of n-Butane and propane on performance and emission characteristics of an SI engine operated with DME-blended LPG fuel, Fuel, Vol. 90, 2011, pp. 1674-1680.

[15] CHEMKIN-PRO 15131, Reaction Design, San Diego, CA, 2013.

[16] Heywood J.B., Internal Combustion Engine Fundamentals, McGraw-Hill, New York, 1988.

[17] Fischer S.L., Dryer F.L., and Curran H.J., The reaction kinetics of dimethyl ether. I: high-temperature pyrolysis and oxidation in flow reactors, International Journal of Chemical Kinetics, Vol. 32, 2000, pp. 713-740.

[18] Curran H.J, Fischer S.L., and Dryer F.L., The reaction kinetics of dimethyl ether. II: low-temperature pyrolysis and oxidation in flow reactors, International Journal of Chemical Kinetics, Vol. 32, 2000, pp. 741-759.

[19] Kojima S., Detailed modeling of n-Butane autoignition chemistry, Combustion and Flame, Vol. 99, 1994, pp. 87-136.

[20] Park S., and Lee C., Combustion performance and emission reduction characteristics of automotive DME engine system, Progress in Energy and Combustion Science, Vol. 39 (1), 2013, pp. 147-168.

[21] Yamada H., Sakanashi H., Choi N., and Tezaki A., Simplified oxidation mechanism of DME applicable for compression ignition, SAE paper 2003-01-1819, 2003.

[22] Ando H., Sakai Y., and Kuwahara K., Universal rule of hydrocarbon oxidation, SAE Paper 2009-01-0948, 2009.

[23] Nakamura Y., Jung D.W., and Iida N., Closed-loop combustion control of a HCCI engine with re-breathing EGR system, SAE paper 2013-32-9069, 2013.

\section{ACKNOWLEDGMENTS}

This research was financially supported by the Ministry of Education (MOE) and National Research Foundation of Korea (NRF) through the Human Resource Training Project for Regional Innovation and Basic Science Research Program through the National Research Foundation of Korea (NRF) funded by the Ministry of Education, Science and Technology (2012R1A1A1044855), funded by the Research for commercialization of DME vehicle of Korea Institute of Energy Technology Evaluation and Planning and Top-Class Agency of School of Mechanical Engineering in University of Ulsan. Also, this work was supported by the Energy Efficiency \& Resources of the Korea Institute of Energy Technology Evaluation and Planning (KETEP) grant funded by the Korea government Ministry of Trade, Industry \& Energy (MOTIE). (20122020100270). 